\title{
IT Requirements Integration in High-Rise Construction Design Projects
}

\author{
${\text { Anastasia } \text { Levina }^{1 *} \text {, Igor } \text { Ilin }^{1} \text {, Rustam Esedulaev }}^{1}$ \\ ${ }^{1}$ Peter the Great St. Petersburg Polytechnic University, Institute of Industrial management, Economy \\ and Trade, 195251, Polytechnicheskaya, 29, St.Petersburg, Russia
}

\begin{abstract}
The paper discusses the growing role of IT support for the operation of modern high-rise buildings, due to the complexity of managing engineering systems of buildings and the requirements of consumers for the IT infrastructure. The existing regulatory framework for the development of design documentation for construction, including high-rise buildings, is analyzed, and the lack of coherence in the development of this documentation with the requirements for the creation of an automated management system and the corresponding IT infrastructure is stated. The lack of integration between these areas is the cause of delays and inefficiencies both at the design stage and at the stage of putting the building into operation. The paper proposes an approach to coordinate the requirements of the IT infrastructure of high-rise buildings and design documentation for construction. The solution to this problem is possible within the framework of the enterprise architecture concept by coordinating the requirements of the IT and technological layers at the design stage of the construction.
\end{abstract}

\section{Introduction}

The rapid development of large cities in Russia led investor-builders and local authorities to a solution of the issue of scarcity of territories and the high cost of land, which is the construction of high-rise buildings, both residential and public. The high-rise building is, on the one hand, the point of economic growth and development center of the given territory, on the other - the challenge to the local infrastructure, the city authorities and the whole system of state building. Effective activities to create high-rise buildings require a certain maturity in the following aspects:

- technological: professionally trained architects, engineers and workers are required; a certain level of development of the building materials industry is needed;

- infrastructure: the development of engineering and social infrastructure in the territory under consideration, good logistics of traffic flows;

- economic: the availability of investors, the willingness of local authorities to contribute to the solution of issues of territorial planning, construction and commissioning of the facility;

${ }^{*}$ Corresponding author: olgakalinina@bk.ru 
- regulatory and legal: the existence of a legislative framework that allows to regulate the design, construction, expertise, operation of constuctions.

Regarding the last point, the construction of high-rise buildings requires special conditions and approaches, while in practice it turned out that normative documents in the field of high-rise construction until recently (until 2017) in Russia were just absent.

The buildings and structures in modern cities are not just a set of building structures. Modern buildings, providing an effective environment for life, must be equipped with a variety of engineering systems, the list of which depends on the functional purpose of buildings and that are the more difficult, the more complex constructed facilities are. Highrise buildings, as a complex technical object, require extra attention to engineering systems. For example, some fire safety requirements and the resulting requirements to ensure the evacuation of people in case of fire at high-rise buildings determine the existence of complex automated systems of devices for the collection and transmission of data on the detection of a fire, that must be transmitted to a single center for processing and decision making. Obviously, the issue of managing the design, creation and subsequent operation of these systems should be payed as much attention as it is payed to creation of the building itself, since without the effective functioning of these systems in the modern world, the building will be just an empty box. Management of the whole set of engineering subsystems of modern buildings is impossible without information technologies. The control system for engineering subsystems of high-rise buildings should provide the ability to monitor the status of various objects, collect, transmit, process information in a single information space. [1] Because of that, the task of the need to regulate the development of an integrated automated control system for engineering systems of high-rise buildings, as well as the development of requirements for the IT infrastructure of the erected object and their accounting when creating project documentation for construction arise. At present, there are no requirements and norms for designing, creating and implementing such a system as part of the high-rise building project.

In view of the lack of a unified concept for the creation of an automated management system and a clear procedure for managing its implementation, approved at the early stages of the construction of a new high-rise building, the following problems may arise [2]:

- spontaneity of the implementation of various subsystems of the information system at different time periods;

- inconsistency of the decisions of various developers and, as a consequence, the lack of the possibility of subsequent integration of individual subsystems into a single information management system;

- increase the cost of implementing individual subsystems;

- achievement of local optimisations at the expense of the effectiveness of the entire management system;

- lack of replicability of expanding the functionality of automated control systems as the enterprise develops;

- usage of solutions that place the customer in dependence on specific performers and manufacturers during the operation phase;

- increase in operating costs.

At the construction phase, all this entails an increased risk of delay in putting the building into operation because of the lack of consideration for the requirements of the IT infrastructure in the construction design. On the operating object the disjointedness of the automated systems leads to [3]:

- subjectivity and significant influence of the human factor on the collection and interpretation of information;

- $\quad$ significant costs for monitoring the reliability of information;

- making decisions based on distorted information; 
- $\quad$ propensity to spontaneously manage deviations;

- permanent overstatement of planned costs for all components of the building management process.

The application of a systematic approach to the construction of a management system that includes as a key component an integrated automated information system and its corresponding IT infrastructure allows to avoid the problems discussed above and minimize the risks associated with them. The implementation of the automated management system and IT infrastructure, coordinated with the stages of construction of the high-rise facility, will allow to eliminate in advance many of the problems that arise in the creation, integration and development of automated systems, as well as reduce future expenses for the modernization and maintenance of the building.

The purpose of this article is to formulate requirements for the IT infrastructure of highrise buildings, which must be taken into consideration at the stage of designing high-rise buildings.

\section{Materials and methods}

To achieve this goal, the following tasks were consistently solved in the article:

- identification of the existing regulatory framework governing the construction of facilities in general and high-rise buildings in particular, also regulating the creation of automated control systems;

- analysis of the existing regulatory framework in the field of building high-rise buildings and the creation of IT infrastructure for the presence of indications of meaningful and chronological harmonization of these standards when creating new facilities;

- search and analysis of publications on the problem of harmonizing the requirements of regulatory documents for construction and the creation of automated management systems and IT infrastructure;

- forming proposals to integrate the requirements for the IT infrastructure into the highrise buildings design phase.

As part of the study, publications on the use of information technologies in construction were analyzed. For example, in [4] it is said that the development of information technology affects construction in general. However, the authors focus not on how information technologies should be taken into account in future buildings, but how the process of modeling, planning, and erecting buildings has changed due to the emergence of information systems of certain classes. These information systems can reduce the labor costs associated with modeling and preliminary tests of models. The same aspect is analyzed in [5].

Forbes in [6] notes that planning is the stage of the project, which should consider the life of future owners of the building, but attention is paid only to the fact that it is necessary to plan the building so that future tenants can live comfortably in it. It is proposed to conduct a survey of future owners.

The following databases were searched to find research or case studies about the issue: Google Scholar, Springer, ScienceDirect, IEEE Explore, Wiley InterScience. As a result, ready templates and techniques were not found in order to have the most efficient and convenient for future users the future structure of information technologies, which will be used by end-users.

In addition to the analysis of normative documents and publications on the problem of the study, during the period from 2015 to 2017 consultations were held with specialists in the field of civil and industrial facilities and related areas (construction companies, industry design institutes, providing companies). All experts confirm the absence of a statutory requirement to harmonize the stages of designing and creating buildings and structures and the stages of designing and developing an automated control system for the building object. 
At the same time, respondents emphasize the need for such an agreement with a view to intime solvation for the problems of integrating construction sites and elements of an automated management system.

To reconcile the requirements of the design documentation for the construction and IT infrastructure, this problem was considered point of enterprise architecture. Enterprise architecture is the commonly used framework of management science in the field of integrated design of business management systems and in a broader context - socio-economic systems. [7-11] The approach to integrated enterprise design based on the enterprise architecture concept is of a universal nature, i.e. applicable for all types of businesses. However, the methodology of designing individual layers and elements of architecture depends on the specific industry.

Within the framework of the enterprise architecture as a complex model of enterprise management, a number of elements, united in the so-called layers. The layers and their elements are interconnected and interdependent: one defines requirements to another one. Layered structure of the enterprise architecture model specifies the relationships between core components of the system. TOGAF [8] defines the following layers of the enterprise architecture: Business, Application and Technology layer. The last one traditionally refers to IT-infrastructure, which is defined by the structure of the Application layer and it requirements.[12] In the meantime, in a broader context Technology layer includes not only IT, but all the physical infrastructure of the enterprise or a system.[13] From this point of view, the physical facilities of the building and its IT-infrastructure has to be designed in parallel and taking into account the requirements of the future IT system of the building.

\section{Results}

It is difficult to overestimate the role of the design stage when creating any object. It is at this stage that all the principles of the functioning of the created system are stated, at this stage it is possible to introduce the required corrections with minimal costs in comparison with the subsequent stages. The cost of fixing errors embedded in the project increases with each next stage of object creation.

After analysis of the approaches of the creation of enterprises and management systems, documented both as regulatory documents and as collections of best practices, three main points of view on this task were identified:

1. point of view of construction;

2. point of view of automated control systems (IT);

3. point of view of the architecture of the enterprise.

The order of enumeration of points of view corresponds to the degree of theoretical elaboration of the approach and the degree of its practicability in practice in descending order. It is advisable to use an integrated approach to the design of the enterprises being created, and the approaches related to the enterprise architecture concept should play an integrating role. [14] Since the constructing of buildings and structures has a much longer history, the construction industry has implemented a full cycle of introducing best practices and technologies into practice: the technologies are scientifically substantiated, fixed in the form of standards, in accordance with which the design of buildings is realized and the examination of finished objects is carried out. The design of the IT component of buildings and structures is a new area of knowledge and also it is dynamically changing. In this regard, despite the existence of state standards for the design of automated systems (GOST 34), there is no unified approach to design, and therefore, and examination of information systems. The development of integrated management systems, including on the basis of the enterprise architecture concept, despite the growing popularity of this area among managers and 
developers of information systems for business, as well as the existence of standards and collections of best practices, this concept is not used in the design of buildings.

Since 2017, the construction and design of high-rise buildings is regulated additionally by the Code of Rules SP 267.1325800.2016 Buildings and high-rise buildings. Design rules [15]. Additional documents are being developed, but none of them (according to official sources) is concerned about the integrated automated management system of high rise buildings. In this document, in addition to the features of the building design of high-rise buildings, it is pointed out that it is necessary to take into consideration in the project numerous engineering subsystems that ensure the operation of such constructions. Thus, the engineering infrastructure of high-rise buildings includes:

- Heating

- Ventilation and air conditioning

- Cold supply

- Water supply, sewerage and watercourses

- Power supply, power electrical equipment and electric lighting

- Communication systems, signaling, automation and dispatching systems (including telephone communication, radio, television, Internet, fire protection system, security system, etc.)

- Vertical transport (including elevators, escalators, etc.)

- Garbage removal

- Safety of functioning and operation of engineering systems

Despite the fact that in the regulatory document SP 267.1325800.2016 Buildings and high-rise complexes. Design rules denote the importance of designing these engineering systems and provides links to the regulatory documents governing the design of such systems, there is no indication of the need to link the content and time of works on the design and implementation of high-rise buildings and engineering systems. In addition, there is no indication of the need to develop and implement a common automated control system for engineering systems of high-rise buildings. Thus, the current regulatory documentation on the design of high-rise buildings regulates the creation of a "material shell" for the future building, but completely misses the issue of creating a "neural network" of the future system, thereby inducing the imperfection of the system being built at the project stage.

It is necessary the structure of the project for the creation of buildings and structures. A typical project consists of 5 stages:

1) Preparatory stage - drawing up a draft of the house, drawing up and coordination with the authorities of documentation permitting construction

2) Zero cycle - excavation, foundation laying and building of the ground floor, laying of communications under the foundation, construction of a common grounding bus

3) Major construction works - building walls and floors, installation of internal partitions and staircases, roofs, exterior finishing

4) Carrying out communications - conducting electricity, running water, sewerage, gas, as well as ventilation and security-fire alarms

5) Interior finishing - installation of interior doors, wall treatment, doing makeover.

In any project activity, the boundary stage, without which the project can not continue, is the planning stage of the project. In the construction projects at this stage is drawn up and the plan for future construction. The plan is necessary in order to understand what result is necessary to obtain at the end of the project.

Because of in the construction after the planning the following stages must follow the plan (this is due to the fact that it is necessary to deliver the object within a specified period, and the slightest deviation from the plan entails an increasing deviation in the final product), the Waterfall model must be used. Features of this model are the following: 
1) each stage must be completed before the next one begins, one can not return to the previous stage (for example, you can not start building walls before foundation is completed)

2) the requirements for the final product are clearly defined (at the beginning of the work, the exact parameters of the building should already be determined)

3 ) there is a fixed cost of work (the cost of the object is determined even before the construction of it)

4) the cost of the error made in the previous stage is extremely high.

At the same time, the stage of writing a plan can take several cycles, which means using the Agile methodology.

For these reasons, it is necessary that a place for future hardware provision be provided at the planning stage. The most common hardware IT services are the following:

- Servers;

- Wiring for power;

- Routers;

- $\quad$ Ethernet wiring;

- $\quad$ Monitors, keyboards and mouse;

It is necessary that the correct placement, that is conducive to convenient and long-term operation, should be provided at the planning stage. The authors compiled a table, which is presented below, in which the main components in the hardware part of any information system are given, with recommendations for planning (Table 1).

Table 1. Objects of IT infrastructure and their place at the design stage of the constructioning

\begin{tabular}{|l|l|l|}
\hline Name of equipment & Equipment place & Notes \\
\hline Servers & $\begin{array}{l}\text { Well-ventilated rooms } \\
\text { with a low degree of } \\
\text { humidity }\end{array}$ & $\begin{array}{l}\text { It is recommended when } \\
\text { planning to allocate rooms of the } \\
\text { ground floor for hosting the } \\
\text { server room }\end{array}$ \\
\hline Wiring for power & $\begin{array}{l}\text { Since the server requires } \\
\text { a large number of } \\
\text { wirings, it is necessary to } \\
\text { provide for deep trenches } \\
\text { in the walls for it }\end{array}$ & $\begin{array}{l}\text { Trenches must be drilled in order } \\
\text { to further increase the capacity } \\
\text { of servers, which means that you } \\
\text { need to add wiring }\end{array}$ \\
\hline Ethernet wiring & $\begin{array}{l}\text { In case if the object is a } \\
\text { residential house, it is } \\
\text { necessary to provide } \\
\text { Ethernet wiring into each } \\
\text { apartment }\end{array}$ & $\begin{array}{l}\text { It is recommended to conduct } \\
\text { cables to the room where Wi-Fi } \\
\text { routers will be located for further } \\
\text { connection with them }\end{array}$ \\
\hline Routers & $\begin{array}{l}\text { Routers should be located } \\
\text { in such a way that the } \\
\text { signal coming from them } \\
\text { reaches each room of the } \\
\text { apartment }\end{array}$ & $\begin{array}{l}\text { Hardware must be installed in } \\
\text { such place where there are no } \\
\text { reflective grids and wiring } \\
\text { between the router and } \\
\text { workstations }\end{array}$ \\
\hline $\begin{array}{l}\text { Monitors, keyboards } \\
\text { and mouse }\end{array}$ & $\begin{array}{l}\text { These accessories do not } \\
\text { need special care, but it is } \\
\text { necessary that it be } \\
\text { installed so that the user's } \\
\text { eyes are not less than 50 } \\
\text { cm (3) (4) }\end{array}$ & $\begin{array}{l}\text { Since it is necessary to have a } \\
\text { minimum distance, while from } \\
\text { the user's point of view, it is } \\
\text { necessary to save space, it is } \\
\text { desirable that these components } \\
\text { are located in a corner or near a } \\
\text { wall. }\end{array}$ \\
\hline
\end{tabular}


Usage of the above recommendations will achieve the following results:

1) The object at the stage of delivery will have an additional competitive advantage, which will make it more attractive to buyers, as a result - the time of sale / rental of premises will decrease;

2) Reducing the costs of future users for the deployment of IT infrastructure due to the lack of costs for preparing premises for servers and components;

3) Increase in the duration of the operational period of the equipment due to the creation of a comfort environment for it.

Since planners and builders do not have extensive knowledge in the field of information technology, it is recommended to involve people with deep knowledge of network and system administration in the process of planning buildings. This concept of creating a plan has a flaw: since more resources are attracted to the planning stage, the cost of the project is increased. These costs can be transferred to the cost of the final product. However, prices in the real estate sector are relatively large, for this reason, the value in relative terms does not increase much, and this does not repel potential buyers.

In conclusion, it should be noted that with the growth of the pace of construction and dissemination of information technologies, the urgency of the problem of integration of the two spheres will increase. Using the tips given in this article, you can avoid a lot of bottlenecks. This will benefit both owners of construction companies who will increase their sales and profits, and end users who will reduce the cost of installing computer equipment.

\section{Discussion}

In this paper, an approach is proposed to take into account the requirements of hardware IT support for high-rise buildings when developing design documentation for construction. The solution of this problem is possible within the framework of the enterprise architecture concept by coordinating the requirements of the IT and technological layers at the design stage of the facility. Consideration of the problem in a broader context presupposes the need to develop an approach not only to harmonize the stages of designing the material objects of buildings and structures and their IT infrastructure, but also to agree on the stages of designing an integrated object management system that includes an information system.

The solution of such a problem is the subject of further research within the framework of the development of the topic touched upon in this article. Such a study requires an in-depth analysis of the regulatory framework for the development of management systems and its alignment with project design documents for construction, as well as studying best practices in the integration of construction standards and the creation of integrated management systems.

\section{Conclusions}

The article highlights the importance of automated management systems and the corresponding IT infrastructure for modern high-rise buildings. The growing role of IT support is due, on the one hand, to the complexity of managing the engineering systems of high-rise buildings, on the other hand, to the requirements of future users of the building infrastructure. Based on the analysis of the existing regulatory framework in the field of creating design documents for construction, including high-rise buildings, the article states the lack of consistency in the development of this documentation with the requirements for the creation of an automated management system and the corresponding IT infrastructure. The lack of integration between these areas is the cause of delays and inefficiencies both at the design stage and at the stage of putting the building into operation. The solution of this 
problem is possible within the framework of the enterprise architecture concept by coordinating the requirements of the IT and technological layers at the design stage of the facility. The article identified the main groups of IT infrastructure objects and proposed a format for accounting for the requirements of these facilities at the design stage of the building.

\section{References}

1. E. Istomin et al International Multidisciplinary Scientific GeoConference Surveying Geology and Mining Ecology Management, SGEM. Volume 1, Issue 2, 2015, Pages 607-614

2. I. Ilin, et al. Enterprise architecture approach to mining companies engineering. MATEC Web of Conferences, 106, 0806. (2017)

3. A.Bril A.R., Kalinina O.V., Ilin I.V. (2017) Small innovative company's valuation within venture capital financing of projects in the construction industry // MATEC Web of Conferences, Volume 106, 08010, International Science Conference SPbWOSCE-2016 "SMART City".

4. URL: http://www.tdx.cat/bitstream/handle/10803/6160/03Nfm03de12.pdf? sequence=3

5. URL: http://www.tandfonline.com/doi/abs/10.1080/01446199400000016

6. URL:https://www.forbes.com/sites/houzz/2013/11/27/6-steps-to-planning-asuccessful-building-project/\#4fda8d083b45

7. M. Lankhorst M. Enterprise Architecture at Work. Modelling, Communication, Analysis (Springer-Verlag, 2013)

8. The Open Group 2009 TOGAF Version 9. The Open Group Architecture Framework (TOGAF). London: TSO

9. URL: http://www.zachman.com/

10. URL: http://cisr.mit.edu/research/research-overview/classic-topics/enterprisearchitecture

11. URL: http://www.gartner.com/it-glossary/

12. A.Anisiforov et al Proceedings of the 29th International Business Information Management Association Conference - Education Excellence and Innovation Management through Vision 2020: From Regional Development Sustainability to Global Economic Growth. 2017, 2920-293 (2017)

13. R.Giachetti R.E. (2012) A Flexible Approach to Realize an Enterprise Architecture. Procedia Computer Science 147-152.

14. A.Bril et al Proceedings of 2017 20th IEEE International Conference on Soft Computing and Measurements, SCM 2017. 6 July 2017, Paper number 7970692, Pages 692-693.

15. Russian Standard SP 267.1325800.2016 